\title{
Experiencia y vivencia. Dimensiones estéticas desde el pensamiento pedagógico de Gabriela Mistral*
}

\author{
Experience and Living. Aesthetic Dimensions from the \\ Pedagogical Thought of Gabriela Mistral
}

\author{
Experiência e vivência. Dimensões estéticas desde o \\ pensamento pedagógico de Gabriela Mistral
}

Dr. Nelson Rodríguez Arratia**

\begin{abstract}
RESUMEN
El presente artículo propone una reflexión sobre la importancia

de la estética como disciplina filosófica en la educación. En este trabajo, hemos optado por los filósofos Hans-Georg Gadamer, de la escuela hermenéutica, y John Dewey, del pragmatismo, con el objetivo de interpretar y analizar, desde sus dimensiones estéticas, experiencia y vivencia, juego, símbolo y fiesta, y la riqueza estética en el pensamiento educativo de Gabriela Mistral. La discusión bibliográfica propuesta como método se justifica en tanto pretende reflexionar sobre la formación en la sensibilidad de quienes participan de todo proceso pedagógico. La novedad radica en que, conjuntamente, filosofía y estética comprenden y proyectan la belleza de las acciones que concluyen en mirar nuestros procesos pedagógicos, más allá de la gestión u otro pro-
\end{abstract}

Palabras clave: Estética, experiencia y vivencia, Símbolo, Juego, Fiesta

\footnotetext{
* Parte de este artículo fue leído, para su posible publicación, en el Seminario: “Discusiones sobre teorías socioculturales y éticas presentes en la práctica del docente de matemática" Realizado en la Universidad Católica Silva Henríquez el 05 y 06 de diciembre del 2018. La ponencia en cuestión llevó por título: "Consideraciones estéticas para la educación". En otros artículos, aún en evaluación, el autor ha trabajado en los escritos pedagógicos de Gabriela Mistral desde la estética cotidiana y la interculturalidad.

** Chileno. Licenciado en Educación, UCBC; Licenciado en Filosofía, Universidad de Chile; Licenciado en Estética, P.U.C; Magister en Literatura, P.U.C; Doctor en Filosofía, Universidad de Chile. Académico de la Escuela de Filosofía de la UCSH. Contacto: nrodrígueza@ucsh.cl

ORCID: https://orcid.org/0000-0002-4878-1374
} 
ceso administrativo, como un elemento de humanidad presente en lo propio de lo humano.

\begin{abstract}
This article proposes a reflection on the importance of aesthetics as a philosophical discipline in education. In this work, we have selected the philosophers, Hans-Georg Gadamer, from the school of hermeneutics, and John Dewey, from pragmatism, in order to interpret and analyze, from aesthetic dimensions, experience and living, play, symbol and festival, and the aesthetic richness in the educational thought of Gabriela Mistral. The bibliographic discussion proposed is justified as it attempts to reflect on the formation of sensitivity in those participating throughout the pedagogical process. The novelty lies in that philosophy and aesthetics, together, understand and project the beauty of actions that ultimately look at our pedagogical processes, beyond the management or other administrative process, as an element of humanity found in the essence of being human.
\end{abstract}

\section{RESUMO}

O presente artigo propõe uma reflexão sobre a importância da estética como disciplina filosófica na educação. Neste trabalho, optamos pelos filósofos Hans-Georg Gadamer, da escola hermenêutica, e John Dewey, do pragmatismo, com o objetivo de interpretar e analisar, desde suas dimensões estéticas, experiência e vivência, jogo, símbolo e festa, além da riqueza estética no pensamento educativo de Gabriela Mistral. A discussão bibliográfica proposta como método se justifica enquanto pretende refletir sobre a formação na sensibilidade daqueles que participam de todo o processo pedagógico. A novidade reside no fato de que, conjuntamente, filosofia e estética compreendem e projetam a beleza das ações que concluem em observar nossos processos pedagógicos, além da gestão ou outro processo administrativo, como um elemento de humanidade próprio do humano.
Keywords:

Aesthetics, experience and living, symbol, play, festival

Palavras-

chave: Estética, experiência e vivência, Símbolo, Jogo, Festa 


\section{Introducción}

Hans-Georg Gadamer, leyendo a W. Dilthey y M. Heidegger, entre otros, propone una estética que se desarrolla en el diálogo entre un sujeto y la obra, siendo la comprensión la posibilidad de dejar hablar a la obra y, a su vez, poniendo en tensión este enfoque hermenéutico con la estética pragmática desarrollada por J. Dewey (2008). Nos preguntamos, entonces, si tanto la hermenéutica como la pragmática abren a la posibilidad de una estética cotidiana. Desde esta discusión, queremos proponer una estética que, por ser cotidiana, es situada y contextual, pues los conceptos de "experiencia” y "vivencia" permiten reflexionar en el pensamiento pedagógico de la poetisa Gabriela Mistral sobre la importancia de la estética en la educación y ejercicio pedagógico.

Asumiendo que la estética funda su reflexión en la sensibilidad del sujeto y que, desde ella, se descubren caminos para conocer y proyectar la vida con los otros y en el entorno, se vuelve necesaria una reivindicación contextual latinoamericana. En este sentido, desde Gabriela Mistral, la formación de la sensibilidad o la importancia de la estética en la educación refiere a una pedagogía que comprende el conocer, el construir y el crear que nacen desde el contacto del sujeto con su historia, con su biografía, con su entorno y con aquellos primeros materiales con los que busca dar sentido a su vida (Fornet-Betancourt). Este saber nace de la experiencia y la vivencia que cada sujeto tiene en su entorno con la tierra y con los demás. Reforzando lo anterior, los sabores, los aromas, el tocar, mirar o gustar son acciones claves para situar una estética que descubre en su contexto un sentido de plenitud, para cada hombre o cada mujer. Muchos de los contextos pedagógicos hoy se articulan en la tensión de lo administrativo, y el conocimiento queda atado a los datos entregados por el profesor que pueda construir el estudiante. Pareciera que la sensibilidad está ajena a todo proceso formativo o pedagógico. Entonces, se trata de pensar la formación como una cuestión atravesada por la sensibilidad. Cómo hacer sensibles a los estudiantes, por ejemplo, en la belleza de lo bueno y lo justo, o en la belleza de encontrarnos en el diálogo o en la conversación. Pero, sobre todo, ser sensibles a la belleza de construir cotidianamente el sentido vital, por el que aprendemos a vivirnos, desde nuestra individualidad, a un nosotros que crece diariamente. 
En el presente artículo se presentarán algunas aproximaciones que nacen desde la estética y que tienen un profundo sentido y relación con la formación o educación. En la primera parte reflexionaremos desde la experiencia y vivencia y cómo estas pueden ser vividas desde las dimensiones de símbolo, juego y fiesta. Para ello, trabajaremos la reflexión inspirados en dos autores que han puesto en relación la experiencia estética y la formación: Hans-Georg Gadamer y John Dewey. La convergencia de ambos propone una discusión sobre la importancia de la estética en la educación.

Las dimensiones estéticas propuestas desde la filosofía tienen un profundo correlato con las experiencias cotidianas en la escuela o en el proceso formativo. Así como la estética ha sugerido la búsqueda de la belleza en el arte, una estética cotidiana busca la belleza en las relaciones diarias, que se fundan en los actores de todo proceso pedagógico, en la experiencia de sentido y plenitud. En esta experiencia ubicamos el pensamiento y la acción de la poetisa y pedagoga chilena Gabriela Mistral, en tanto aporte a una educación de la sensibilidad desde una estética cotidiana.

\section{Formación. Entre la vivencia y la experiencia}

En el contexto contemporáneo, en el que las ciencias de la naturaleza o la racionalidad técnica proponen un dominio analítico que, incluso, determinan las formas de las relaciones humanas, y en este sentido: “...cada recuerdo del arte es un correctivo a ese carácter unilateral de la orientación moderna del mundo" (Gadamer 1998). Para Dewey, la experiencia del arte o la experiencia estética propiamente tal es parte importante en la formación del hombre, pues esta funciona como vivencia en las experiencias de cada sujeto, es decir, como posibilidades de interacción del sujeto con el medio, pues "en la relación entre individuo y medio, pueda transformar de manera efectiva las condiciones dadas" (Carreras 74)

En ambos autores la filosofía, desde la estética, entraña una forma de comprender al hombre respecto de su mundo, pero también de comprender cómo el hombre, desde la estética, busca la sensibilidad para reflexionar y proponer atisbos de solución a los diagnósticos culturales contemporáneos. La educación estética, en este sentido, puede concebirse como el despliegue que la sensibilidad otorga a la forma- 
ción tanto del conocimiento como del mismo saber, que no solo se comprende desde los procesos cognitivos o racionales, sino también sensibles respecto de lo humano y su provenir (Varona 118)

Ya lo advertía el filósofo y poeta F. Schiller en sus Cartas sobre la educción estética del hombre, en las que ponía como defectuosa una educación que, para formar el carácter moral, lo hacía sacrificando el carácter natural de lo humano y, más aún, declaraba como "una constitución muy imperfecta, que solo suprimiendo la multiplicidad consigue establecer unidad". Prosigue Schiller, que:

... se debe privilegiar el carácter subjetivo y específico del carácter; que para extender el reino invisible de la moralidad no es preciso entenebrecer al mundo de la apariencia [Y es que todo artista, como político y pedagogo habrán de respetar] "la personalidad, y característica del material sobre el que trabaja... (el hombre) para la intimidad de su ser (21-22)

De este modo, tanto la estética como la filosofía imprimen un carácter relevante a la formación de la sensibilidad de los hombres. Más allá de considerar el arte o las obras de arte como parte importante en la formación de la sensibilidad, las experiencias que viven los estudiantes en una institución educativa también requieren ser pensadas de acuerdo con un horizonte en que la belleza sea considerada desde los actos cotidianos. En todo contexto pedagógico, el aprender, así como el enseñar, juega un papel protagónico, pues se trata de que cada uno de los actores comprometidos, por lo próximo el profesor y el estudiante, descubran en cada una de las acciones un sentido, que abra a la comprensión del propio sentido vital.

$\mathrm{Al}$ respecto, Gadamer propone una reflexión desde el concepto de bildung. La formación es clave a la hora de pensar desde la experiencia estética el fenómeno educativo. Pues, desde la formación, confluyen en la reflexión la condición histórica del individuo, el diálogo y la sensibilidad. En la formación se nos desafía a mirar "a algo más elevado y más interior, al modo de percibir que procede del conocimiento y del sentimiento de toda la vida espiritual y ética, y se derrama armoniosamente en la sensibilidad y el carácter" (Gadamer 1991 39). Uno de los aspectos importantes en la bildung es la formación del tacto. Éste no es solo una cuestión de sentidos, ni una mera comprensión psicologista 
de lo humano. El tacto es un modo de ser y conocer, por el que el hombre se permite mirar su vida en el continuo de su historia, la tradición y el contexto en el que se desarrolla (Gadamer 1993 46). El tacto es uno de los puntos en los que estética y ética se encuentran, y otorgan un sentido clarificador y de alta pertinencia a nuestros procesos pedagógicos:

... precisamente porque vivimos en un mundo cada vez más estrecho, donde la inminencia y frecuencia del roce y del choque se ve inevitable, es más necesaria que nunca esta educación del tacto. Tacto para tratarme, para tratar al otro, para tratar a lo otro. Estamos en el mundo, pero más que eso somos parte del mundo, el mundo es parte de nosotros. Es parte de mí el agua, el aire, el fuego, la tierra. Mi tacto está comprometido con el hombre nunca lejano, siempre prójimo próximo. Pero también con el animal, con la planta, con la piedra (Sepúlveda 27)

De este modo, la educación ha de considerar la formación del tacto, y no solo como una cuestión asociada a la epidermis. La formación del tacto confiere relevancia a la educación, pues implica la formación en un modo de ser, de vivir y convivir. Aquí proponemos las nociones de vivencia y experiencia, como elementos claves en la formación. Dilthey caracteriza a la vivencia como aquella unidad por la que el tiempo del sujeto queda dotado de significación: "cada unidad más abarcante de partes de la vida, vinculadas por un significado común para el curso de la vida, incluso allí donde las partes está separadas unas de otras por procesos que la interrumpen" (Dilthey 2008 119) Siguiendo la reflexión de Dilthey, Gadamer, indica que vivencia es reflexividad e interiorización, aquello que entrega el sentido de nuestro ser y estar en la historia, pues lo que sucede en la historia no son meros datos, sino unidades de sentido y significado. Por esta razón, la vivencia será siempre una re-traducción de las objetivaciones de la vida a la vitalidad espiritual de la que ha surgido. De este modo, la vivencia otorga una forma de conocimiento, por la que el ser uno mismo adquiere una ganancia en la misma formación (Gadamer 1993). Así, la vivencia es aquella experiencia por la que nuestra vida encuentra su sentido y significado, que supone una forma de conocer y sentir nuestra existencia y unidad (uno mismo) en el devenir histórico. Una vivencia es aquel claro por el que podemos mirar y comprender nuestra vida, nuestra historia. Al decir 
de Gadamer, una vivencia es una referencia interna a la vida misma (Id. 104).

Ahora bien, si la vivencia comprende ya el significado de ser uno mismo, la vivencia desde la experiencia estética es la que alcanza una plenitud en el conjunto del sentido de la vida. "Una vivencia estética contiene siempre la experiencia de un todo infinito" (Id. 107). Así, la vivencia refiere desde la comprensión y el significado del propio sentido de la vida a comprender la propia vida como una experiencia estética, pues asume la contemplación de la vida como una obra de arte. Sin embargo, la experiencia estética no solo se vincula con el arte, sino más bien con una unidad que está dada por la experiencia estética de la vida. Al respecto, Dewey propone a la experiencia estética como una unidad entre la vida y la cotidianidad. La experiencia estética:

En vez de significar encierro dentro de los propios sentimientos y sensaciones privados, significa un intercambio activo y atento frente al mundo; significa una completa interpenetración del yo y el mundo de los objetos y acontecimientos. (...) es la experiencia del arte en germen. Aún en sus formas rudimentarias, contiene la promesa de esta percepción deliciosa que es la experiencia estética (Dewey 2008 21).

La experiencia estética como una experiencia de vida elevada, significa, según Dewey, que aquello que irrumpe como obra de arte concierne a la más íntima experiencia cotidiana, es decir, aquello que vivimos y construimos todos los días con los materiales dispuestos alrededor y con los otros, medio por el que nuestra vida se eleva a la plenitud, que es el goce del grupo humano o de la comunidad que nos rodea. Agrega Dewey:

A fin de entender lo estético en sus formas últimas y aprobadas, se debe empezar con su materia prima; con los acontecimientos y escenas que atraen la atención del ojo y del oído del hombre despertando su interés y proporcionándole el goce mientras mira y escucha... [tales cosas] en su propio tiempo y lugar son medios para exaltar los procesos de la vida cotidiana... y pertenecen al despliegue de proezas, a la manifestación de solidaridad del grupo o del clan, al culto de los dioses, a las fiestas o ayunos, a la lucha, a la casa y a todas las crisis rítmicas que puntuaban la corriente de vivir (2008 5). 
Así, desde la estética, la formación consistirá en mirar nuestras prácticas cotidianas, los objetos con los que trabajamos y que son parte constitutiva de nuestra experiencia y, sobre todo, propiciar que esa experiencia de plenitud sea posible para que un estudiante descubra en ellas su vivencia. La vivencia, como el momento de significación vital, requiere siempre del empeño permanente de buscar aquellas experiencias que son conducentes a ella. De este modo, habría una estrecha relación entre lo que expresamos por experiencia y vivencia. Una antigua idea propone el filósofo Eugenio Ímaz en la traducción del texto de Dewey (1952). Según Ímaz, la coincidencia más importante entre Dewey y Dilthey está dada entre lo que uno llama "experiencia" y el otro "vivencia". Para Dewey, todo conocimiento trae de suyo la vida estética, pues ofrece al hombre plenitud en el ir y venir de lo que comparte y construye. Y la vivencia se comprende desde esas experiencias; como diría Dilthey, la vivencia es aquella experiencia que, por no ser la vida infinita, ofrece momentos de gozosa infinitud.

Si bien Dewey sugería hablar de "experiencia" y "vivencia", la primera es referida al encuentro del hombre con el medio y la segunda al encuentro consigo mismo hacia el mundo. La experiencia estética cobra alto sentido al momento de pensar la educación, pues esta no trata solo de cuestiones de conocimiento, sino además de sentir la plenitud en el ejercicio de transformación del mundo vivido (Carreras 73). La palabra "vivencia" fue utilizada por el filósofo español Ortega y Gasset para traducir el término alemán Elebnis y, sea dicho de paso, este concepto también es traducido por "experiencia": "que es una vetustísima palabra, que expresa una vetustísima vivencia” (Acevedo 72). Lo que experimentamos en la vida no puede quedar fuera de nuestra vivencia, pues se trata de que lo vivido comprenda un sentido de pensar y construir horizontes, es decir, un proyecto por el que la vida descubra y construya significados.

Desde esta relación entre experiencia y vivencia, queremos abordar y proponer una estética que, desde el arte, permita la comprensión del sujeto (Gadamer), permita mirar nuestro cotidiano como los primeros materiales de una experiencia o vivencia de plenitud (Dewey). Se trataría de considerar una estética cotidiana. Así como el hombre se descubre en una obra de arte, también es posible generar una comprensión desde lo que se vivencia en el ámbito educativo. Una estética 
cotidiana que se hace cargo de proponer reflexiones y experiencias por las que el sujeto, al mismo tiempo que se descubre en su sentido vital, se descubre también como sujeto comunitario, esto es, parte de una sensibilidad común. La estética cotidiana es un modo de reconocer que aquello que verdaderamente aprendemos lo hacemos por y desde la sensibilidad. Es precisamente en este punto en el que la estética cobra su real importancia en educación (Marini et al.). La importancia de esto se evidencia al mirar nuestro cotidiano y ver cómo aquellas experiencias contenidas en él se descubren como vivencias. Pues, de este modo, la formación permite comprender que el conocimiento se construye desde la sensibilidad que abre a cada sujeto a la comprensión de su vida personal y social. Efectivamente, es en la formación donde el sujeto se descubre como sujeto histórico. La historia emerge desde sí mismo cuando las experiencias despiertan las vivencias.

De lo anterior, nos proponemos presentar algunas reflexiones sobre las dimensiones estéticas para pensar la importancia de la estética en la formación. Sin duda, en esta relación entre vivencia y experiencia se requieren precisiones sobre sus dimensiones estéticas, para lo que sugerimos su abordaje a través del juego, el símbolo y la fiesta.

\section{Dimensiones estéticas}

Hacer referencia a las dimensiones que a continuación se proponen es un esfuerzo que permite abrir la reflexión sobre la importancia de la estética en la educación. Más allá de pensar el cómo, que sin duda será una revisión, se trata de pensar el desde dónde. Hablar de juego, símbolo y fiesta, sugiere Gadamer, es situarse en la misma experiencia del arte. Sin embargo, el mismo filósofo aclara que, al ser antropológicas estas dimensiones, permiten mirar de manera estética la vida misma del hombre (Gadamer 1991).

\section{a. Juego}

Según Gadamer, el juego ha desempeñado un papel de suma importancia en la estética, y lo que aquí buscamos es liberar el concepto de cualquier significación subjetiva y de asumirlo solo como un estado de ánimo o comportamiento del que crea o disfruta. Se trata de reconocer en el juego el propio modo de ser de la obra de arte. Es decir, expuestos a una obra de arte, nos dejamos hablar por ella, nos sentimos declara- 
dos por ella. El diálogo que se crea en el ser hablado y hablar de una obra de arte es la experiencia del lenguaje que nace de la estética. Entonces, la experiencia estética se fundaría en el juego, en la experiencia de jugar que da la experiencia del lenguaje. De este modo, lo propio de la conciencia estética es la reflexión del juego como tal, es decir, aquello que se juega en el jugador (Gadamer 1993 143). Así, la importancia del juego, aunque reconocida su seriedad por parte del jugador, estriba en el juego mismo. Primero, porque la experiencia con la obra de arte y la conciencia estética, por la que los jugadores emprenden el diálogo, es en la experiencia de jugar. Segundo, porque existe juego en la medida en que desaparece, por decirlo de algún modo, el «ser para sí» de la subjetividad que limita el horizonte temático de la misma experiencia, es decir, es el jugar el que abre el espacio de la subjetividad a una construcción que busca implicancias.

Lo propio del juego, entonces, sería la transformación que experimentan los jugadores. De este modo, el movimiento como el automovimiento de un jugador es la autorrepresentación del jugador, en la medida en que juega. En la experiencia estética el juego comienza a jugar en nosotros y nos hacemos juego en su movimiento. "El juego es, en definitiva, autorrepresentación del movimiento del juego" (Ibíd. 68). El juego - el jugar y el ser jugados- propone otra mirada. Pues en la experiencia de ser jugados sentimos nuestros propios cambios respecto del jugar. Así, la experiencia del juego es una experiencia de transformación en construcción. Cada vez que juego, cada vez que me entrego al sentido del juego, descubro que me voy haciendo distinto a lo que era. No es la negación de lo que lo que he sido, sino su expansión como búsqueda de sentido, y es esa experiencia de sentido lo que se nos manifiesta como lo verdadero.

Nuestro giro «transformación en una construcción» quiere decir que lo que había antes ya no está ahora. Pero quiere decir también que lo que hay ahora, lo que se representa en el juego del arte, es lo permanentemente verdadero “(...) es así por el que el juego humano alcanza su verdadera perfección; la de ser arte” (Ibid. 154-155).

No obstante, el hecho de que el juego alcance su perfección en el ser arte no reduce esta realidad a una obra. Nos referimos a una experiencia más profunda que mirar una obra como un objeto. Aquello que se contempla en un poema, un cuadro, un drama o un escenario, 
perfectamente puede ocurrir en la vida. Si miramos nuestras acciones, los objetos con los que interactuamos a diario o las personas con las que conversamos, son posibilidades de construir nuestros sentidos vitales, pues lo que se ha llamado "construcción" es transformación en construcción: "lo es en cuanto que se presenta, a sí misma, como una totalidad de sentido" (Ibíd. 182). El juego abre a la comprensión. Desde la experiencia hermenéutica, la experiencia estética queda asumida en ella, pues se trata de un conocer que pertenece al mundo del sujeto, por el que este mismo se comprende. Desde el juego, el mundo, para cada uno, es la posibilidad de comprenderse, pues jugar en este sentido significa

que se pertenece al ser de lo que se comprende... y decir que la comprensión forma parte del ser de lo que se comprende significa que no es mero método que acceda a la verdad como si este fuera un objeto exterior al que tuviera que conformarse, sino que la propia verdad del ser, la cosa misma, en suma, se constituye en el comprender (Gutiérrez-Pozo 38-39).

Tal vez por la misma razón aparece la experiencia de la conversación como una experiencia en la que jugar y ser comprendido como un ser transformación y en construcción sea una experiencia propia de estar abierto a una totalidad de sentido. Por ello, nos dejamos jugar en la medida en que existe un otro que nos abre desde el juego a construir lo que aún no somos. Jugar es descubrir aquello que nos falta de ser. Conversar y jugar tienen un correlato existencial profundo, pues desde lo que juego en la conversación, se descubren y aprecian los sentidos que me descubren como persona. Como advertíamos, el juego nace en la experiencia de uno con la obra de arte en tanto experiencia en el lenguaje, y, en este sentido, la conversación entre unos y otros permite pensar algo similar. Para Dewey, la experiencia de conversar tiene un profundo sentido de formación. Se trata de que cada educador converse con sus estudiantes, pues en la conversación se aprende a apreciar lo que de sentido tiene para uno y para otro la vida. La experiencia, para Dewey,

debe formularse para ser comunicada. Para formularla se requiere salirse de ella, verla como la vería otro, considerar los puntos de contacto que tiene con la vida de otros, para que pueda adquirir tal forma que aquel sea capaz de apreciar su sentido (Dewey 2009 17). 
Todo juego que se provoca en la conversación es el modo de reconocernos en lo que somos y en lo que podemos ser. Jugar en la conversación consiste en ir en ella sin saber su destino, pero construyendo un horizonte en el que un tú y un yo se reconocen y cooperan en la construcción de sus espacios vitales y del propio sentido de vida.

\section{b. Símbolo}

En el juego que se da en la conversación descubrimos la importancia de la palabra como símbolo. De más está recordar que los conceptos revisados, como "símbolo", se comprenden en la apreciación estética del arte. Pero no son solo eso, sino que además se infieren como dimensiones antropológicas que permiten la comprensión de la vida misma del hombre en la construcción de su sentido vital. Para Gadamer, la palabra "símbolo" viene de la lengua griega, significa «tablilla del recuerdo" y se refiere a la relación que establece el anfitrión con su huésped. El primero, al aceptar la entrada de un huésped, partía una tablilla, quedando una mitad para cada uno y, en un próximo encuentro, ambos podían reconocerse uniendo los dos pedazos de tablilla. De este modo, existiría una relación de conocimiento de algo antiguo, por lo que correspondería una cierta unidad de significado entre ambos; como advierte Gadamer, una tessera hospitalis que, en una particular traducción, sería una entrada a la hospitalidad (Gadamer 1991 84). De este modo, la experiencia simbólica se transforma en una vivencia, pues en la experiencia estética con la obra de arte cada sujeto descubre una particular forma de entrar al juego, que permite comprenderse. Esa coincidencia que se descubre permite la comunicación de aquello que les hace encontrarse. Es en la experiencia simbólica de la conversación donde hablamos de ese reconocerse en un tú y un yo por el que se juega un camino, un sentido o un proyecto de vida. En el hecho de que un símbolo pueda ser una tablilla del recuerdo podemos también ver que éste es, a su vez, el recuerdo de algo que nos falta - nos falta la otra mitad de la tablilla-. De este modo, en la relación con el símbolo se comprende que algo se descubre como faltante en mi historia, lo que da cuenta de la posibilidad de completar un orden íntegro faltante. Así, el símbolo, la experiencia de lo simbólico,

quiere decir que este individual, este particular, se representa como un fragmento de Ser que promete complementar un todo íntegro 
al que se corresponda con él; o, también, quiere decir que existe el otro fragmento, siempre buscado, que complementará, en un todo nuestro propio fundamento vital (Gadamer 1991 85)

Lo simbólico, según Gadamer, no es solo una referencia entre significados, sino que es el propio ser sensible que descubre significados. Es algo que, al descubrirle, muestra algo más que ese mismo significado. Lo faltante, como experiencia de lo simbólico, es lo que se muestra como un documento que reconoce a los miembros de una comunidad, sea este una señal, un gesto, una palabra. El significado del símbolo reposa en cualquier caso en su presencia, en la actualidad de ser mostrado o dicho (Gadamer 1991 110). En este sentido, bien vale insistir en que la relación entre el maestro y el estudiante puede ser comprendida como una experiencia simbólica, pues ambos se reconocen partícipes de una comunidad y, al mismo tiempo, de aquello que es manifiesto o dicho, como lo es contar una historia, narrar un cuento o hablar con amabilidad. Estas son acciones que la sensibilidad reconoce como faltantes y que dejan el registro de aquello íntegro, que nos encamina a la plenitud de lo humano en nuestra historia.

De este modo, la experiencia con el símbolo abre a la dimensión de nuestra plenitud vital. Si ya en la experiencia de jugar descubríamos cómo vamos siendo transformados y en esa transformación hay construcción de la vida, el símbolo no solo nos muestra lo faltante, sino que, por ser manifiesto, dice también qué hemos de cambiar. Ya lo decía Goethe y lo recuerda el mismo Gadamer: todo es símbolo y casi de una manera poética nos habla y nos dice "haz de cambiar tu vida" (1998 62)

De lo anterior se entiende la importancia de la recursividad simbólica para el proceso educativo. Si recordamos que el símbolo es una experiencia por la que nos reconocemos tensionados en el ser y desde nuestro propio ser buscamos sentidos, el símbolo se vuelve un puente entre lo que somos y lo que queremos ser. Cruzar este puente es, de algún modo, la experiencia vital del interpretar y el comprender. Por ello, el proceso educativo debe también considerar una comprensión que establezca distintas experiencias, sean de orden sensible o inteligible, en las que el sujeto aprende a comprender y a interpretar:

El campo de la acción humana del sujeto implica necesariamente la experiencia sensible y la experiencia inteligible. Por ello, una 
educación desde la hermenéutica no sólo debe rescatar y promover la experiencia inteligible mediante la formación de conceptos, sino que, reconfigurando la experiencia sensible, debe ser puente de unión con la experiencia inteligible al interpretar y recrear el universo simbólico, modo específicamente humano construido mediante imágenes sensuales y transmitido multigeneracionalmente (Avilés y Valladares 179).

Tal vez, una de las experiencias necesarias en todo proceso educativo sea la experiencia del conversar. A propósito de la formación y el tacto, o de la formación en la sensibilidad, la experiencia simbólica en el conversar es el reconocimiento que en ella se establece entre un tú y un yo, y se descubre un mundo por el que reconocemos nuestro carácter histórico, en el que "cambiar nuestra vida, sea una apetencia de sentido y experiencia común":

El carácter fundamental del ente histórico es ser revelador, ser significativo, en el sentido activo de la palabra; y ser para la historia es dejarse que algo signifique. Solo así surge la auténtica vinculación entre el yo y el tú; solo así se constituye entre nosotros y la historia lo vinculante del mundo histórico (Gadamer 1994 41).

De este modo, quien comprende el diálogo como una experiencia del tacto, en el que cada uno descubre al otro en la medida en que se profundiza, se abre a una experiencia simbólica que nos sitúa en el corazón de nuestro ser histórico, pues en el lenguaje descubrimos cuán vinculante es cada palabra con cada una de nuestras historias.

\section{c. Fiesta}

Desde la experiencia del juego y del símbolo llegamos al concepto de "fiesta". El reconocimiento que despierta una relación simbólica en el lenguaje de la conversación permite el reconocernos como comunidad. En este espacio incumbe plantear el concepto de "fiesta", pues esta es la experiencia en que lo celebrado se trasforma en vivencia, ya que, como reunión de todos en un tiempo y un espacio, se construyen horizontes comunes. Dado lo anterior, es necesario indicar cómo los tres conceptos desarrollados convergen entre sí. Por la conversación somos transformados, desafiados a trabajar la propia existencia desde lo que nos falta de ser, desde lo que nos falta de sentido, aprendiendo aquel lenguaje que permite encontrarnos en una experiencia de lo co- 
mún, que nos integra y nos reúne en esa condición que respeta a cada uno en lo que es. Pues:

Si hay algo asociado a la experiencia de la fiesta, es que se rechaza todo el aislamiento de unos hacia otros. La fiesta es comunidad, es la presentación de la comunidad misma en su forma más completa. La fiesta es siempre fiesta para todos (Gadamer 1994 99).

Cuando la experiencia práctica no está en el centro de la formación y el conocimiento, solo se despliega desde aquello que la ciencia dice, el trabajo docente y la experiencia del diálogo se debilitan, al punto de vaciar el trabajo mismo. Esto en relación con la fiesta, pues ella misma es una experiencia de unidad, pero la técnica y su exacerbación en el ejercicio docente permiten decir que el trabajo, en vez de ser una experiencia que reúne, separa. Y nada más lejos de la fiesta que la separación o exclusión. Cuando la técnica se apropia del lenguaje en la formación, lo que podemos comprender por "fiesta” solo se entenderá en un tiempo no asociado al cotidiano y menos al quehacer educativo propio de la formación. Se podría creer, de algún modo, que la fiesta se explicaría como otro tiempo dentro del que se vive. Pero esa no es la apuesta de Gadamer, pues la fiesta no nos saca del cotidiano cuando se da desde el diálogo, el encuentro y el reconocimiento; en "la fiesta todo está congregado" (Gadamer 1994 100).

Si bien el concepto de "fiesta" no es tratado en propiedad por Dewey, sin embargo, en la experiencia estética, la unidad de lo individual y lo colectivo, la unidad material de cada experiencia, esto es, la coherencia entre lo intelectual y lo práctico, son propias de un sujeto que percibe y logra ver la consumación del trabajo en el producto planificado y terminado, cuyo sentido y utilidad son de alto valor en el crecimiento de lo humano. De este modo, el enemigo de lo estético no será lo práctico o lo intelectual, sino lo mediocre, lo que queda a medias o lo que no alcanza esa unidad vital entre lo que el sujeto siente, vive y proyecta en su vida. Claramente una experiencia estética cotidiana para Dewey es aquella que logra ser percibida como y en su consumación, es decir, cuando el sujeto logra sentir y ver que la vida puede ser proyectada (Dewey 2008 47). Por lo anterior, podemos decir que existe fiesta en la medida en que un estudiante, un niño o un joven, logra ver que hacia dónde camina tiene significados y sentidos en que proyectar la vida en su más pleno sentido de con- 
sumación. En este aspecto, al ver la coherencia entre idea y práctica, y cómo la realidad se construye y se transforma, podemos sentir, casi como el arquitecto al fin de la obra, que las cosas han sido bien pensadas y bien hechas.

Entre las concepciones de Gadamer y Dewey se encuentra una noción de tiempo que el sujeto descubre como el tiempo propio y el tiempo para los demás. Bajo la noción de "fiesta" este tiempo es aquel en el que, desde el congregarnos, cada uno se remece en lo personal para asumir en propiedad la vida y la comunidad. La experiencia del tiempo ideal de la fiesta, que permite comprender y reunir el juego y el símbolo, es el tiempo que llega. Como si llegara para quedarse, pues abre lo diferente, anuncia algo como distinto y desafía la propia historia personal para hacerse en ella por nuestra vida: "es lo que llamamos el tiempo propio, y lo que todos conocemos por nuestra propia existencia vital" (Gadamer 1991 104). Para Dewey, la experiencia del tiempo como fiesta dice relación con la comprensión del ocio, pues insiste en las experiencias del ocio como cuidado y condición para el desarrollo perdurable de los hábitos del espíritu. Dewey habla del goce del ocio, pues en esta experiencia los niños comprenden que a la vida le corresponde lo propio y personal (Dewey 2009).

El filósofo y esteta chileno Fidel Sepúlveda entrega una profunda descripción sobre el real sentido de la fiesta. Es el mismo cotidiano en que el sujeto rompe la rutina para volverla extraordinaria, pues su experiencia vital es la experiencia de la unidad del cuerpo y el alma, de lo visible y lo invisible, de lo audible y el silencio, de la individualidad y la comunidad y, sobre todo, es aquella experiencia y vivencia que nos conecta con nuestra identidad de ser:

... la fiesta nos revela lo mejor de lo visible, pero sobre todo la experiencia de que lo esencial del ser del hombre y del mundo es lo invisible; que lo audible es la portentosa voz del universo como armonía y como estridencia, pero que lo más sobrecogedor es lo inaudible, la voz del ser profundo del cual el sonido es lo inaudible, la voz del ser profundo del cual el sonido es apenas un balbuceo; que el olor y el sabor son resquicios e intersticios por los que escapa el ánimo de revelación y entrega de la esencia de las cosas: que el tacto deja su condición de límite y se transforma en frontera del ser del hombre y del mundo, donde los otros internos y externos se en- 
cuentran en el gran nosotros, en el tacto mayor del encuentro con la identidad (Sepúlveda 2005 94).

La noción de símbolo en la conversación lleva a descubrir lo que de ser nos falta. En el juego de conversar, reconocernos, encontrarnos y proyectar la vida, la experiencia de la fiesta es, sin duda, la experiencia que abre a las vivencias de la sensibilidad. Así, la experiencia de educar se ve enriquecida desde la estética, pues formarse sería estar en una permanente seducción por lo bello de nuestra vida. Son esos nobles sentimientos los que construyen el hábito permanente de espíritus creadores, críticos y transformadores.

\section{Experiencias estéticas cotidianas. Consideraciones desde el pensamiento pedagógico de Gabriela Mistral}

Hoy, en el contexto educativo o pedagógico encontramos distintos distractores, que impiden a un profesor pensar o vivir en una comprensión de su quehacer respecto de sus estudiantes. Solo por mencionar algunos: el exceso de una psicología que desatiende el conocimiento por acentuar las metodologías y las didácticas, un discurso fuertemente homogeneizador que fortalece la capacitación o domesticación de la misma vida individual por la mirada técnica, entre otros. Como consecuencia, el rol del profesor se encuentra desafiado por el mismo contexto y no por lo que en algún momento comprendió la formación o (menos) la bildung, es decir, por el sentido de comunidad y de humanidad que está llamado a formar (Merino).

Desde el correctivo que puede anunciar tanto el arte como la formación a la sensibilidad en un contexto educativo, en el que las escuelas sufren por demostrar resultados que respondan a las expectativas estandarizadas por sistemas de cualificación, se olvida "aquello que se considere valioso en la educación" (Marini et al. 2). Entre las cuestiones olvidadas, la sensibilidad, el tacto y todas aquellas experiencias vividas en la escuela que favorecen la formación de un hombre, que desde los olores, los colores, la ambientación del espacio, los sonidos, las texturas del ambiente, la sencillez del conversar, van en la línea de una estética cotidiana "que puede ser significativa, ya que facilitaría el acercamiento de la sensibilidad como un modo de conocer, promoviendo la vinculación entre percepción y estructuras de nuestra conciencia" (3). 
En la línea de lo anterior, la poetisa y educadora chilena Gabriela Mistral ilumina respecto de cómo todo proceso pedagógico debe considerar que cada experiencia da oportunidades de vivencias, por las que los estudiantes puedan sentir que lo aprendido tiene proyección y sentido. Cuando en el proceso pedagógico el conocimiento se vuelve exclusivamente académico, o cuando las relaciones entre el maestro y los estudiantes se transforman en el traspaso de información, sin el candor o la delicadeza del lenguaje: "La pedantería magisterial ha cumplido su primera barbaridad y queda rota la cosa única que había que mantener íntegra desde el primer día de escuela: la confianza" (33). Mirar lo cotidiano es mirar nuestras experiencias, y mirar nuestras experiencias es descubrir que en cada vivencia se encuentra un modo de conocer, de sentir y proyectar, que une la experiencia estética no solo con el arte sino con nuestra vida. Pues, en el río de nuestras vivencias, la experiencia estética es la que nos comprende más allá de una racionalidad técnico-científica, que nos presenta como objetos de nosotros mismos, sin vivencias ni sentido.

Si desde una estética cotidiana miramos nuestra escuela, y en ella queremos descubrir que cada espacio y construcción relacional entre estudiantes y profesores se presenta como un lugar de vida comunitaria,

se da por supuesta la existencia de una construcción que alberga, protege y ofrece un espacio de trabajo y juego. También se tiene la expectativa de relaciones humanas, compromisos y proyectos que se desplegarían en ese lugar. Pero la escuela en tanto "lugar de vida comunitaria" no se agota aquí. Se proyecta desde el contexto material e intersubjetivo hacia objetos de valor simbólico, como las imágenes en las salas de clases, los colores institucionales, los puntos "ciegos" del patio o campo de deportes, las puertas de los baños, los sonidos y olores del recreo, entre otros signos que pueden ofrecer referencias de diálogo y convivencia (Marini et al. 11).

Mirar el cotidiano en sus experiencias como vivencias permite recuperar el sentido histórico de un sujeto, permite comprender que, bajo ambos conceptos, el hombre descubre su sentido de vida y su sentido de mundo. Las experiencias y vivencias en la escuela forjan un sentido de plenitud en el hombre que da cuenta de que la vida se construye. La sensibilidad como formación recupera un sentido esencial en los procesos educativos y, sobre todo, como una estética cotidiana que 
encarnan los maestros al respecto. Por eso, Gabriela Mistral dice que todo maestro se ocupa:

[de] la salud del niño, a la defensa de su gozo natural, a un entrenamiento minucioso de los sentidos, al desperezar de la fantasía, al espíritu de convivio, a un cuido delicadísimo de las intuiciones y, sobre todo, el mantener el calor y los modos familiares. Nada tienen ellos que hacer con la pedagogía del ceño fruncido, con la lengua empalada, con la escuela-cuartel de Hitler y tampoco con la de mero jolgorio (Ibíd. 237).

Por esta razón, miramos la formación desde la noción de "tacto": el tacto, desde una comprensión primera, es aquello que nos toca y hace sentir tocados por una experiencia que funciona desde la epidermis. Tacto, además, posee una comprensión que no solo estriba en un análisis psicológico, sino en una cuestión que atiende al sentir profundo. Esto es, cómo lo tocado, o lo que me toca, es un umbral por el que descubro una posibilidad de sentido de vida. De este modo, conocer, no solo implica saber aquello que el profesor dice en el aula, sino, sobre todo, cómo eso que dice es un problema, una cuestión o reflexión de sentido vital. Por eso, y en este sentido, la conversación es una acción estética que se forma en el tacto. Conversar un contenido en el aula, como también en el camino que transcurre de un aula a otra, son instancias propicias para ir aprendiendo los ritmos de la conversación. Sin embargo, hay otras experiencias estético-cotidianas, que podemos nombrar, como, por ejemplo, cuando el profesor comparte el almuerzo en el comedor con los estudiantes: conversar sobre lo que se come, ver los colores en el plato, el orden de las proporciones, conversar sobre los sabores, la relación de los alimentos con la tierra y su cuidado, la producción del hombre. De este modo, diría Mistral, “el paladar no se acuerda de fruta ácida ni segundona... mis manos [así] retienen todavía la habilidad y el gusto de escoger" (109). Son estas cuestiones que miran y consideran al tacto como un elemento articulador en la formación. La sensibilidad no es entonces solo una cuestión de epidermis, sino aquello que adviene cuando miramos, respiramos, saboreamos, palpamos, o bien advertimos desde el cuerpo que hay un proyecto por realizar. La experiencia estética desde el tacto nos sitúa en la experiencia propia de un sujeto en la historia, es decir, descubrimos que somos historia y que en ella hay sentido. 
Una estética crítica también es capaz de ver cómo el contexto de la globalización neoliberal afecta nuestras relaciones en el gusto y el tacto: la aceleración del tiempo sin vida, la comida chatarra - muchas veces repartida en los comedores de la escuela-, las salas sucias y desordenadas, como si en ellas no hubiese personas que conviven. Todas experiencias que denuncian a la escuela en una mitología seudoilustrada sobre ese modo particular moderno de la educabilidad del hombre. Recuerda Mistral la importancia de todo proceso pedagógico, de lo que ocurre en el aula y de su correlato con la vida:

... hay que matar el dogma pedagógico, pero hay que cuidarse mucho de crear otros. La discusión teórica debe marchar en forma paralela a la experimentación práctica. Entonces nos acordaremos de aquel refrán popular: «otra cosa es con guitarra». No hay trabajo de reforma hecho en pura asamblea. Hay que ir al campo de la experimentación. Hay que convertir la idea en acción (129).

Tal vez lo anterior sea un argumento más que permita plantear la necesidad de incorporar las nociones de juego, símbolo y fiesta, para comprender cómo la experiencia estética permite comprender la educación, el ejercicio pedagógico y la relación educativa como una experiencia de belleza, tal como podemos gustar de un buen libro, un buen poema, un exigente ejercicio matemático o de los movimientos del cuerpo. El profesor, desde una comprensión simbólica, desafía siempre a considerar nuestras acciones pedagógicas, para que sean estas un modo de encontrarse del estudiante en su vida en su "qué hacer" respecto de su proyecto vital. El profesor, nos recuerda Mistral, desde el símbolo, procura siempre generar encuentros. Al maestro no lo priva ni el concepto, ni la academia, ni la intelectualidad para buscar en cada relato una experiencia de belleza, pues el profesor logra: "Vivir las teorías hermosas. Vivir la bondad, la actividad y la honradez profesional. Ameniza la enseñanza con la hermosa palabra, con la anécdota oportuna y la relación de cada palabra con la vida" (29).

Es impensable una escuela donde la palabra "juego" no cumpla una experiencia radical en la formación. Jugar permite encuentro, ser seducido por la búsqueda de estrategias y normas por las que poder competir; pero advierte también sobre la capacidad de discernir y pensar. En esa experiencia, el sujeto descubre además que es cuerpo y no solo un logos dispuesto a un aprendizaje sin movimiento. En el 
movimiento del juego un sujeto, desde el cuerpo, también se descubre en sus pasiones, sus limitaciones y en aquello que necesita para transformarse. Jugar es un modo de construir en la escuela una poética del cuerpo. También jugar es la experiencia de ser transformado, de estar abierto y en construcción, es el primer paso a la comunicación humana, pues exige siempre un jugar-con. El juego también puede comprenderse como una experiencia comunicativa. Así como desde el juego entramos en diálogo con la obra de arte, también entre uno y otro podemos encontrar, en la experiencia del juego, la comunicabilidad, el reconocimiento y el sentido. La experiencia hermenéutica, como diálogo, nos ubica en aquello por lo que deseamos jugar y por lo nos abandonamos al juego, pues lo que se nos exige, en definitiva, es la búsqueda de sentido (Gadamer 1993 68).

Si el juego es característico de la obra de arte, y si la vida, como obra de arte, abre a la comprensión del sentido, el juego es la experiencia inevitable por la que se entra a una forma de búsqueda y de encuentros en los que la dimensión propia de lo humano desafía e impele en lo más íntimo. La transformación en construcción a la que invita la obra -la vida - nos pone en situación de permanente juego y experiencia de estar abiertos a lo que se juega. El juego da alegría, recuerda Mistral:

... la alegría (de jugar) es la que conoce su destino celeste y su misión en la vida; la que por saber mirar delicadamente el mundo, lo ve hermoso y sutil; la que por impulso de amor... ama a los seres (...) entre ellos amándolos aun cuando viva en lucha con ellos, por imponerles una mayor nobleza en sus horas (122).

En este sentido, la conversación, como una experiencia permanente de construcción y transformación, nos ubica en la tensión de que lo que somos está siendo y puede ser de otra manera, para comprender cómo la experiencia del juego es relevante en la experiencia de la formación. Paulo Freire decía que el espacio del juego era el espacio propicio de la formación, pues era la hora en la que los niños echaban el alma afuera (Freire 44). La expresión deja en claro que la experiencia del juego es una experiencia de apertura otorgada por el lenguaje, cuestión que, para Mistral, se aprende mirando el paisaje y no solo en el aula: "Una de las mejores lecciones de pedagogía que he recibido, me ha sido dada por una avecilla (pechi-rojo). Estaba en el jardín y la madre le enseñaba volar a sus pequeñitos..." (52). Más aún, hoy en el 
cuidado de la tierra, Mistral evoca esta referencia: "Observé que las niñas, que en clase solo «reciben», en el campo o en un huerto «dan», preguntan, piensan, se interesan "por la tierra toda»" (114). Así, la conversación entre un profesor y un estudiante remite a una experiencia simbólica que resulta vital para comprender que el proceso educativo consta de experiencias que requieren ser interpretadas, para ubicarnos en la tensión hacia horizontes que comprometen nuestro despliegue de vida. Para Latinoamérica, la experiencia del relato, como la de conversar, sugieren la proyección de la comunidad, pues contienen

una función particularmente pedagógica y formativa... [pues] implican a la totalidad del sujeto, comprometiéndolo; llama la atención tanto su compromiso afectivo, como intelectivo, puede ser transmitido de generación en generación, permite una actualización y renovación a lo largo del tiempo" (Avilés y Balladares 181).

El relato, como contar en una clase, se encuentra tanto en el conocimiento como en la humanidad que nos aflora, cuando la confianza nos hermana en el saber. El maestro también es un contador, decía Mistral: "El contador ha de ser sencillo y hasta humilde si ha de repetir sin añadidura fábula maestra que no necesita adobo; deberá ser donoso, surcado de gracia en la palabra, espejeante donaire, pues el niño es más sensible que Goethe o que Ronsard a la gracia" (61).

De algún modo, entendemos que un maestro se esfuerza en hacer del enseñar un encuentro con aquello que queda expuesto a un encuentro con la belleza y la sutil verdad. El estudiante que llega a la escuela trae consigo un puñado de mitologías y fábulas, y ese niño es también un símbolo, pues es la experiencia de jugar.

El niño, hasta el más infeliz, llega a la escuela trayendo su mitología, (su relato) un puñado chiquito de fábulas recibidas unas en la falda de una madre contadora, otras de boca de la vecindad... Había que oírle primero y ver el modo de usarle ese pequeño tesoro, (...) por valorizarle lo único que trae y abrirle con esto la confianza (...) [Para] Contar de nuevo, metiendo lo que falta... hasta dejársela incorporada en su contorno cabal (Mistral 31-32).

Entonces, será el maestro quien, escuchando, abre en la experiencia del lenguaje, mediante la conversación, la posibilidad de que él y el niño puedan encontrarse en la palabra que falta para construir la obra 
maestra que es la vida, que se vuelve plena en la experiencia de apreciar el sentido de uno y otro. Esta es la experiencia de la fiesta: "No hay otra fiesta en la relación escolar, que la de una confianza desatada” (50)

Insistir en la relación del símbolo, el juego y la fiesta es abrir la posibilidad de pensar la relación pedagógica más allá de los saberes técnicos, administrativos o didácticos, que muchas veces ponen el énfasis en el desarrollo de habilidades por sobre las experiencias o vivencias de sentido entre el docente y el estudiante. Sería hermoso pensar que el ejercicio pedagógico, el ser docente, es un proceso por el que se descubre ser maestro, pues en el juego de la conversación se descubre cómo hablar-les y cómo hablar-se. Se descubre lo que carece de ser para transformarse en quien acompaña, mismo proceso por el que el estudiante logra descubrir su ser discípulo.

\section{Conclusión}

Contemplar una obra de arte nos envuelve en un diálogo, casi amoroso, sobre lo contemplado y, al mismo tiempo, sobre lo que nos habla de la propia vida respecto de la obra: la obra dice, habla. Esta experiencia, que a menudo se considera propia o exclusiva de la experiencia estética respecto del arte, también es posible de interpretar la misma belleza en nuestras acciones cotidianas. Una obra de arte, como el mundo relacional y experiencial de una escuela, también dicen que se puede transformar la belleza contemplada en la plenitud de un sentido vital. Se trata de comprender que toda experiencia contiene una vivencia y, a su vez, ambas permiten hablar de la formación en la sensibilidad. Ella es la condición de todo aprendizaje. De este modo, la estética no es solo una forma de mirar, sino también una forma práctica, por la que sus efectos construyen una realidad que reconoce la tensión entre la individualidad y la comunidad. Al mirar la escuela, por ejemplo, no solo debemos ver sus asignaturas: no se trata de más arte o menos, sino de mirar todas las prácticas de convivencia que afectan la sensibilidad para los aprendizajes, que son proyectos para la vida.

Los mismos sentimientos que asoman en lo contemplado en una obra de arte se despiertan también al contemplar lo cotidiano. Esa es la habilidad de un maestro que, desde el encuentro con un estudiante, desafía la experiencia de la sensibilidad al reconocer que el cotidiano implica la belleza de lo bueno, del cuidado de sí, de los demás y de 
la tierra. De este modo, la experiencia estética se vuelve también una experiencia estética cotidiana, como lo confirma nuestra poetiza y pedagoga Gabriela Mistral. En este sentido, se pide mirar más las prácticas que anteponer ideas en las relaciones humanas en una escuela. La formación docente debe estar en un permanente diálogo con aquello que nutre las distintas nociones de belleza. Las experiencias, aclara Mistral, permiten sugerir que la formación implica reconocer la sensibilidad de cada integrante de la comunidad educativa. Nos ubicamos como sujetos en la historia desde la experiencia simbólica y abrimos diálogos, juegos, para despertar los sentimientos que sitúan cada vida, cada historia, en un terreno de fecundidad, para cultivar las cosas, los motivos, los conceptos que alimentan nuestro sentido de vida. Sea este el desafío de ser maestro.

\section{Bibliografía}

Acevedo Guerra, Jorge. "Pensando la vida cotidiana con Humberto Giannini". Limite. Revista Interdisciplinaria de Filosofía y Psicología 11.37 (2016): 66-75.

Avilés, Mauro y Balladares, Jorge. "El símbolo en la experiencia latinoamericana y su incidencia para la enseñanza de la filosofía". Sophia: colección de Filosofía de la Educación 19.2 (2015): 173-188. DOI: https://doi.org/10.17163/soph.n19.2015.08.

Carreras, Carla. "John Dewey: En el principio fue la experiencia". Utopía y Praxis latinoamericana 21.72 (2016): 69-77.

Dewey, John. Democracia y educación. Barcelona, España: Paidós, 2004.

Dewey, John. Democracia y escuela. Madrid: Popular, 2009.

Dewey, John. El arte como experiencia. Barcelona, España: Paidós, 2008.

Dewey, John. La búsqueda de la certeza. México: FCE, 1952.

Dilthey, W. Dos escritos sobre hermenéutica: el surgimiento de la hermenéutica y los esbozos para una crítica de la razón histórica. Madrid: Istmo ediciones, 2000.

Fornet Betancourt, Raúl. La interculturalidad a prueba. Aachen: Wissenschaftsverlag Mainz, 2006.

Freire, P. El grito manso. Argentina: Siglo Veintiuno Editores, 2012.

Gadamer, H.-G. Estética y Hermenéutica. Madrid: Tecnos, 1998. 
Gadamer, H.-G. La actualidad de lo bello. Barcelona: Paidós, 1991.

Gadamer, H.-G. Verdad y Método I. Salamanca: Sígueme, 1993.

Gadamer, H.-G. Verdad y Método II. Salamanca: Sígueme, 1994.

Gutiérrez-Pozo, Antonio. "El arte como realidad transformada en su verdad. La rehabilitación hermenéutica de la estética en Hans-Georg Gadamer". Kriterion: Revista de Filosofía 59.139 (2018): 35-54.

Marini, Guillermo, Merchán, Juan David Rodríguez y Macarena Salas Aguayo. "Estéticas cotidianas escolares: desde lo que se ve hacia cómo se siente la escuela”. Educação \& Sociedade 39.143 (2018): 361-378. DOI: https://dx.doi.org/10.1590/ es0101-73302018171876

Merino, M. J. “Educación, natalidad y poder en Hannah Arendt”. Ensayos en torno al sentido de la educación. Ed. Maximiliano Figueroa. Santiago-Chie: RIL editores, 2017. 53-68.

Mistral, Gabriela. Gabriela Mistral. Pasión de enseñar. Valparaíso-Chile: Editorial UV (Universidad de Valparaíso): 2017.

Schiller, Friedrich. Cartas sobre la educación estética del hombre. Madrid: Colección Universal,1920.

Sepúlveda, Fidel. "Estética: Educación de los sentidos y sentido de la educación". Aisthesis, 29 (1996): 25-30. Disponible en http:// revistaaisthesis.uc.cl/index.php/rait/article/view/906/854 Acceso 14 de octubre de 2019.

Sepúlveda, Fidel. "Fiesta y vida”. Aisthesis 38 (2005): 92-98. Disponible en http://revistaaisthesis.uc.cl/index.php/rait/article/ view/500 Acceso 14 de octubre de 2019.

Varona, Freddy. "Una mirada humanista a la educación estética de la sensibilidad humana". Aisthesis 60 (2016): 111-128. Disponible en file://C:/Users/Ucsh/Downloads/Una_mirada_ humanista_a_la_educacion_estetica_de_la.pdf 